\title{
Sobre a presença do esporte na escola: paradoxos e ambigüidades
}

\author{
Jaison José Bassani* \\ Danielle Torri** \\ Alexandre Fernandez Vaz ***
}

\begin{abstract}
Resumo: trata o presente de resultados parciais de uma pesquisa em andamento, cujo objetivo é estudar aspectos da educação do corpo na escola. Foram estudadas aulas de Educação Física e atividades de Esporte Escolar de uma grande escola pública de Florianópolis, por meio de observações sistemáticas e entrevistas. Os resultados apontam para a prevalência do esporte e seus vetores na Educação Física, como paródia de si, e para a ambigüidade do Esporte Escolar, oscilante entre os imperativos da competição e os discursos sobre a formação humana via práticas esportivas.
\end{abstract}

Palavras-chave: Esporte Escolar, Educação Física, Educação do Corpo, Indústria Cultural, Teoria Crítica da Sociedade.

Todos sabemos do enorme prestígio conferido às práticas esportivas na sociedade contemporânea. O século vinte foi do esporte, e tudo indica que o presente também se fixe em seus valores e normas, mantendo-o como uma de suas referências centrais. Afinal, ele representa, como poucos outros fenômenos, a ideologia do sucesso, da auto-superação, da rejeição aos limites, do progresso corporificado e individualizado nas imagens dos atletas. São eles e elas os ícones da beleza, os exemplos de obstinação, de renúncia, de auto-sacrifício a serem seguidos. Não

* Licenciado em Educação Física, Mestrando do Programa de Pós-Graduação em Educação da Universidade Federal de Santa Catarina, bolsista da CAPES, membro do Núcleo de Estudos e Pesquisas Corpo, Educação e Sociedade (CED/UFSC/CNPq).

** Estudante do curso de Licenciatura em Educação Física da Universidade Federal de Santa Catarina, bolsista do programa PIBIC/CNPq-BIP/UFSC, membro do Núcleo de Estudos e Pesquisas Corpo, Educação e Sociedade (CED/UFSC/CNPq).

*** Doutor em Ciências Humanas e Sociais pela Universidade de Hannover, Alemanha, Professor do Departamento de Metodologia de Ensino e do Programa de PósGraduação em Educação da Universidade Federal de Santa Catarina, coordenador do Núcleo de Estudos e Pesquisas Corpo, Educação e Sociedade (CED/UFSC/CNPq).

Movimento, Porto Alegre, v. 9, n. 2, p. 89-112, maio/agosto de 2003 
é à-toa que treinadores de equipes e de atletas de sucesso são chamados para palestras em empresas e associações de classe, e que escrevem livros de auto-ajuda.

Como índice da sociedade contemporânea, o esporte mostra sua força ao sobreviver a um dos principais fatores que, paradoxalmente, é responsável pelo seu incessante desenvolvimento, o uso de fármacos para melhoria da performance. Observase grandes atletas que mantêm-se como referências morais para as crianças e jovens, deixando intocável o conjunto de patrocinadores que os sustenta e também o sistema esportivo em geral, responsável por girar, com extrema velocidade, a roda da indústria de entretenimento.

Também nos ambientes escolares, como sabemos, o esporte tem uma destacada presença. Tanto como conteúdo central da Educação Física Escolar, quanto como prática extracurricular, os esportes são motivo de canalização de importantes recursos financeiros, materiais e simbólicos nas escolas brasileiras. O discurso oficioso diz que esporte é um fator fundamental para a educação das crianças e jovens, atribuindo-se a ele freqüentemente papéis admiráveis, como livrar as pessoas do consumo de drogas.

O esporte escolar resistiu até mesmo ao ataque desferido por uma parcela do pensamento crítico da Educação Física brasileira nos anos oitenta e noventa, que o relacionou diretamente à ditadura militar e aos mecanismos de opressão política e sujeição do corpo. A celebração das práticas esportivas não apenas sobreviveu a este ataque - que em meio aos evidentes devaneios, apontou e desenvolveu uma crítica muitas vezes pertinente e progressista - como também voltou hoje a ser uma das bandeiras contemporâneas da inclusão social. O governo federal anuncia como uma de suas realizações o projeto Terceiro Tempo, que visa atender com atividades esportivas crianças e jovens no período contrário ao da escolarização regular. O governo anterior, já no seu epílogo, e possivelmente motivado pela "mobilização" que se deu "em favor" da Educação Física por conta do suposto fracasso nos Jogos Olímpicos de Sidney, já havia instituído o programa Esporte na Escola. ${ }^{1}$ Volta a esperança de que nas práticas esportivas esco-

1 Sobre o programa Esporte na Escola e o embaralhamento entre esporte e Educação Física, manifesto também nas políticas públicas, consultar o artigo de Bracht e Almeida (2003). A respeito do suposto fracasso brasileiro nos Jogos Olímpicos de 2000 sugerimos, entre outros, Vaz (2001a).

Upvimento Porto Alegre, v. 09, n. 2, p. 89-112, maio/agosto de 2003 
lares se promoverá o acesso à cidadania, e de que destas experiências surgirão nossos futuros campeões. O atual governo federal, por meio de suas empresas estatais, é o grande fomentador do esporte de alto rendimento no Brasil.

Compreender um pouco melhor a presença do esporte nos ambientes escolares é o objetivo do presente texto, que trata de alguns resultados de uma pesquisa mais ampla, ${ }^{2}$ que, dentre outros objetivos, procura entender a intrincada relação entre a escola, conhecimento e cultura sintetizadas por meio da educação do corpo. Nossas perguntas rondam os atores/sujeitos que compõem o esporte na escola, tanto o que constantemente se atualiza na Educação Física Escolar quanto aquele que encontra lugar no aprendizado e treinamento específico de uma modalidade. Sabemos que o corpo não é educado apenas por meio dos esportes e das outras práticas presentes na Educação Física Escolar, mas em vários tempos e espaços que compõem as múltiplas dinâmicas de escolarização. Atemo-nos no presente trabalho apenas a alguns aspectos das práticas esportivas, tanto na Educação Física quanto, principalmente, no Esporte Escolar institucional. ${ }^{3}$

2 A pesquisa é parte do Projeto Integrado de Pesquisa Esclarecimento, Racionalidade e Educação na Teoria Crítica da Sociedade: Bildung e Aufklärung na/a partir da obra de Theodor W. Adorno, realizado com apoio dos programas FUNPESQUISA/UFSC/ 2002 e PIBIC/CNPq-BIP/UFSC. Os dados compõem também um projeto interinstitucional que realizamos junto com colegas e alunos da Universidade Federal de Goiás (Goiânia e Catalão) e da Faculdade de Pato Branco, denominado Da educação do corpo em ambientes escolares: retratos e cruzamentos em uma perspectiva comparada, que também conta com apoio do programa PIBIC/CNPqBIP/UFSC. Uma versão preliminar do presente texto foi apresentada no I PréConbrace Sul, em Pato Branco, junho de 2003.

3 Nesse registro, pensar a educação do corpo e as práticas corporais na escola sem que se considere o contexto maior em que se insere o corpo no mundo contemporâneo parece pouco sensato, na medida em que a escola, como um dos espaços privilegiados no qual as culturas de uma sociedade, de forma dinâmica, se desdobram, se reforçam e se fragmentam, não escapa ilesa aos espaços que o corpo alcançou como vetor privilegiado na construção de identidades. Dito de outra forma, a escola, por meio da Educação Física - disciplina importante, mas não a única que diz respeito à educação do corpo - absorve, interpreta e trabalha concepções e práticas corporais presentes em outros tempos e espaços da sociedade (VAZ, 2001b). A educação contemporânea não está excluída desse processo, e a educação do corpo na escola não é exceção. Um exemplo é a forte presença de esportes e outras atividades corporais, com espaço marcante na mídia, nos espacos e tempos escolares. Outro exemplo é a crescente preocupação de crianças e jovens com as próprias imagens corporais, estruturadas em hierarquias que devem responder aos mutantes padrões contemporâneos de beleza, vários deles vinculados à composição corporal. Ganham força, nesse quadro, as técnicas corporais de embelezamento, muitas vezes propostas pela Educação Física.

Movimento, Porto Alegre, v. 9, n. 2, p. 89-112, maio/agosto de 2003 
Nossa perspectiva considera os destinos do esporte nos desígnios da indústria cultural, uma das marcas fundamentais da sociedade contemporânea. Referimo-nos não somente à produção ou transformação do esporte em mercadoria para o consumo, mas aquilo que configura, nos termos da produção reificadora de subjetividades, a indústria cultural como um espírito do tempo: a celebração e disciplinarização da dor e do sofrimento corporal, a referência moralista ao esporte de alto rendimento, as regras de submissão às hierarquias escolares, as ambigüidades da pedagogia esportiva (entre os imperativos da performance e os discursos do aprendizado dos "bons valores").

O tema da indústria cultural remete, como é sabido, à Teoria Crítica da Sociedade da Escola de Frankfurt, principalmente a Theodor W. Adorno. Junto com Max Horkheimer ele foi o primeiro a empregar o termo, no clássico Dialética do esclarecimento. O conceito deveria substituir, com mais precisão, o de cultura de massas. A idéia era, e é, não confundir uma cultura produzida popularmente com a produção segundo os mecanismos e espírito da indústria. Não obstante, trata-se de pensar a degradação e a banalização da alta cultura em entretenimento para as massas, segundo um esquema a ser repetido - que Adorno chamará de esquema da cultura de massas (Das Schema der Massenkultur) - e, mais do que isso, uma nova forma de produzir diversão, já na origem desinibida de qualquer pretensão de conhecimento ou expressão de profunda humanidade, mas imiscuída no mero objetivo de, como qualquer diversão, fazer esquecer o sofrimento (HORKHEIMER e ADORNO, 1997; ADORNO, 1997a, 1997b).

Como nem o esporte nem a educação - e, por conseguinte, a pedagogia esportiva - podem ser entendidos fora do contexto mais amplo da sociedade contemporânea, parece-nos que ainda é necessário pensar estas questões no contexto da indústria cultural. Fazemos isso sabendo que este exercício é, de certa forma, pensar contra o espírito desse tempo, que faz encolher o pensamento crítico, que considera os ardis reificadores como não problemáticos.

No próximo item descrevermos um pouco o contexto do campo investigado, além de expormos alguns elementos do instrumental de investigação. Logo depois atemo-nos mais diretamente ao material empírico coletado, quando então algumas questões mais propriamente metodológicas - e não apenas instrumentais ficarão mais claras. Ao final, concluímos com algumas conside- 
rações e pistas tanto para o prosseguimento do programa de pesquisa do qual este texto faz parte, quanto para outras investigações. Ainda de início, é preciso dizer que o presente texto procura dar prosseguimento a um esforço que busca aprofundar a reflexão teórica no campo educacional articulada com investigações empíricas, algo que temos realizado, como já foi indicado, a partir do projeto frankfurtiano de um materialismo interdisciplinar.

\section{II}

Nosso campo de investigação é um grande colégio público localizado na região central de Florianópolis, que dispõe de condições materiais positivamente incomuns para as escolas brasileiras: oito quadras poliesportivas, ginásio coberto, pista de atletismo, salas específicas para aulas de danças e lutas marciais, número expressivo de profissionais disponíveis, apoio para participação em eventos competitivos, etc.

Os motivos que nos levaram a escolher esse campo de investigação remetem, por um lado, ao caráter multifacetado da instituição, que recebe alunos de todas as idades e de várias camadas sociais, oriundos da Ilha de Santa Catarina, do continente e das cidades circunvizinhas a Florianópolis. Por outro, é a única escola de Santa Catarina que tem dois departamentos que tratam diretamente da educação do corpo, já que ao tradicional Departamento de Educação Física soma-se o de Esporte Escolar. Não há cobrança de mensalidades no esporte escolar, mas de uma "contribuição espontânea", de valor reduzido. Enquanto o primeiro departamento trata da Educação Física escolar, disciplina curricular obrigatória, o segundo promove atividades esportivas, tanto de aprendizado das modalidades, quanto de treinamento para competições federativas oficiais, atendendo não apenas os/as alunos/as da escola, mas também a comunidade em geral.

Enquanto a existência conjugada de dois departamentos vem desde o início dos anos 1990, o lugar privilegiado do esporte escolar no campo investigado remonta ao início dos anos 1970. Em 1973 foi fundada a associação que representa a escola em competições diversas, inclusive em federações do sistema esportivo formal, e que coincidia desde então, com o setor de esportes do departamento de Educação Física. Este foi extinto no

Movimento, Porto Alegre, v. 9, n. 2, p. 89-112, maio/agosto de 2003 
final dos anos oitenta, como decorrência da então proposta curricular para a Educação em Santa Catarina, voltando na forma de um departamento, portanto com muito mais força institucional, $\log$ o a seguir.

Os critérios para a divisão das turmas no Departamento de Esportes são basicamente os mesmos utilizados pelo Departamento de Educação Física, com uma pequena variação no que diz respeito ao critério de faixa etária. No primeiro, ao contrário do que parece acontecer no segundo, a idade dos/as alunos/as-atletas é de fundamental importância na organização das turmas de treinamento, uma vez que as competições nas quais a associação esportiva participa são definidas, como é costumeiro, a partir de categorias estabelecidas de acordo com a idade do/da atleta.

As aulas de Educação Física, por sua vez, desde a quinta série do ensino fundamental ocupam-se exclusivamente dos esportes, um por semestre e por turma, ficando livre a opção de matrícula para os/as alunos/as. No entanto, é facultativo aos alunos e alunas a opção de freqüentar simultaneamente aulas e treinos em ambos os Departamentos. Segundo nos revelou uma professora, esta dinâmica de funcionamento foi adotada "há bastante tempo", e a mudança teria ocorrido em virtude da "perda de espaço" - a preferência dos/as alunos/as - do Departamento de Educação Física em relação a seu congênere de Esporte Escolar (RlA, 25/06/02). ${ }^{4}$ Como se verá ao longo do trabalho, o esporte institucionalizado ocupa um lugar destacado na cultura escolar, relegando as práticas da Educação Física a um plano secundário. E curioso observar, no entanto, que a própria Educação Física repete, ainda que de forma caricata, a dinâmica do Esporte Escolar, não optando por um modelo que lhe seja alternativo, mas reitera-o, mesmo com clara inferioridade de realização.

Os/as alunos/as freqüentam as aulas de ambos os departamentos em período contrário ao da sala de aula, ou seja, aqueles/as que estudam de manhã presenciam as aulas/treinamentos no período da tarde e vice-versa. As aulas de Educação Física possuem duração de 48 minutos e acontecem duas vezes por

4 As citações dos cadernos de campo são realizadas indicando o número do relatório e a data correspondentes à seqüência das aulas observadas. A letra " $A$ " indica que o relatório refere-se ao caderno de campo das observações das aulas de Educação Física, enquanto a "B" indica que pertence ao conjunto de observações do Esporte Escolar. As citações referentes às entrevistas seguem o mesmo padrão adotado nas citações dos cadernos de campo.

Movimento Porto Alegre, v. 09, n. 2, p. 89-112, maio/agosto de 2003 
semana, sendo que em um dos encontros realiza-se "aula-faixa" (dupla), totalizando então três encontros. Os treinamentos do Esporte Escolar realizam-se também duas vezes por semana e cada sessão possui duração de uma hora.

Nesta primeira etapa da investigação, foram observadas aulas de Educação Física de duas turmas da modalidade de futsal, uma masculina e outra feminina, ministradas por uma professora. As observações, orientadas por um roteiro, aconteceram durante nove semanas na turma masculina e oito na feminina, perfazendo um total quatorze aulas observadas na primeira e doze na segunda. Os meninos que faziam parte da turma de futsal observada eram oriundos de sextas e sétimas séries, a maioria estudantes da mesma turma de sétima série. A situação das meninas era semelhante. No entanto, uma vez por semana a turma se unia a outra turma de futsal, formada por meninas que estudavam em séries do ensino médio.

No caso do Esporte Escolar, acompanhamos sessões de treinamento de um grupo de alunos/atletas da categoria mirim da modalidade de futsal, cujas idades variavam de dez a doze anos. Durante sete semanas foram observadas seis sessões de treinamento desse grupo. Nesse período também foram coletados dados em três partidas oficiais da equipe, referentes à fase semifinal e final do Campeonato de Futsal da Grande Florianópolis. Os treinamentos eram ministrados por um professor formado em Educação Física que, embora estivesse vinculado administrativamente ao Departamento de Educação Física Escolar, estava cedido ao Esporte Escolar. A maioria dos alunos/atletas estudava na própria escola, mas havia alguns oriundos de outras instituições, inclusive da rede privada. Também foram entrevistados/as professores/as, alunos/as, pais e mães. Consideramos, ao escolher as crianças para as entrevistas, a posição que elas ocupavam no grupo: aquelas que o/a professor/a considerava como o/a melhor e o/a pior aluno/a, segundo seus próprios critérios também eles são elementos que compõe as fontes.

Os resultados têm sido analisados qualitativamente, reunidos em conceitos articuladores/condensadores formulados a partir do cruzamento entre os objetivos e as expressões próprias dos objetos de investigação. Uma premissa está sendo considerada em todo o transcorrer da pesquisa, que se refere ao que chamamos prioridade do objeto - Vorrang des Objekts (ADORNO 1997c): a necessidade de permitir que suas múltiplas vozes se manifestem.

Movimento, Porto Alegre, v. 9, n. 2, p. 89-112, maio/agosto de 2003 
Considerando os limites do presente trabalho, selecionamos, para fins de apresentação e discussão dos resultados parciais, dois conceitos articuladores que agrupam vários dos aspectos observados, e que permitem, por meio deles, estruturar um discurso sobre alguns aspectos da educação do corpo nesse ambiente educacional. O primeiro conceito articulador, que diz respeito ao conjunto de observações referentes às aulas de Educação Física, procura evidenciar a relação entre a organização pedagógica das aulas, sobretudo seus aspectos metodológicos, e os rituais de disciplinamento corporal. O segundo conceito, que se refere ao conjunto de observações do Esporte Escolar, procura evidenciar a tensão e as estratégias de conciliação entre o rendimento esportivo desejado/esperado dos alunos/atletas, tanto nos treinamentos quanto em competições oficiais, e o aprendizado de "bons valores" por meio da prática esportiva.

\section{Educação Física: organização pedagógica e rituais de disciplinamento}

Em relação às aulas de Educação Física, a análise preliminar dos dados revela um elemento surpreendente: das vinte e sete aulas previstas para a turma masculina, apenas quatorze delas aconteceram. O caso foi ainda mais grave na turma feminina, para a qual foram ministradas apenas doze aulas de um total de vinte e cinco. ${ }^{5}$ A principal razão para o baixo número de aulas está relacionada à estrutura administrativa da Educação Física no ambiente pesquisado, que prevê a não realização das aulas em dias de chuva. No caso das turmas observadas, foram precisamente sete aulas do grupo masculino e cinco do feminino que não aconteceram devido às intempéries climáticas. Outros motivos também contribuíram, como a participação da professora de Educação Física em atividades previstas no calendário da escola (entrega de boletins e "dia de qualificação") e a participação em evento para-científico da área. Em algumas ocasiões, a própria professora deixou de ministrar uma das aulasfaixa em virtude do comparecimento de pouco/as alunos/as. Tal fato foi registrado em nosso caderno de campo, onde se lê: “...an-

5 Uma situação semelhante, ainda que não tão drástica, foi encontrada em outra pesquisa em escola pública (VAZ; BASSANI; SILVA, 2001).

Movimento Porto Alegre, v. 09, n. 2, p. 89-112, maio/agosto de 2003 
tes do início das atividades, a professora comentou que, com o número reduzido de alunos na aula - 'esse pingo de aluno', disse ela - limitaria o horário para apenas uma aula, ao invés de duas como estava previsto" (R2A, 26/06/02).

O fato representa um paradoxo interessante para entendermos não apenas a dinâmica das aulas de Educação Física no ambiente em questão, mas a forma como esta disciplina, muitas vezes, se organiza nas escolas. Por um lado, a Educação Física cumpre a expectativa, talvez imaginária, de que é um espaço importante para cumprir as exigências legais em relação à estrutura curricular. Por outro, fica evidente - especialmente pelo fato de não ter havido em nenhum momento, nem por parte da professora nem dos/as alunos/as, a cogitação de reposição dessas aulas -, que apesar dela possuir uma "importância legal", sua função pedagógica é dispensável, ou no mínimo inferior às demais disciplinas. Esse paradoxo parece colocar em xeque a crença de que a Educação Física teria um papel curricular destacado. A própria professora da turma afirma, em entrevista, que o lugar social da Educação Física seria marginal em relação a outras disciplinas, ocupando-se com a compensação e recuperação psicofisiológica das atividades mais duras realizadas cotidianamente na escolarização. Mais de uma vez, de diferentes formas, ela repetiu esse vaticínio nas aulas (R11A, 09/08/02; R12A, 19/08/02; E1A, 21/11/02).

Uma outra questão observada é a forte determinação do modelo esportivo, e dos rituais de disciplinamento corporal por meio dele, nas aulas de Educação Física. Esse fenômeno, tantas vezes referenciado pela literatura da área, ${ }^{6}$ continua presente. Ele aparece, segundo temos observado, em várias de suas faces. A primeira delas é nos rituais pedagógicos vinculados à estrutura do treinamento corporal que, com pequenas variações, segue a tradicional estrutura do aquecimento, parte principal e volta à calma. Nossas anotações trazem o tema de forma exemplar:

...a professora mandou os alunos correrem sobre a linha amarela da quadra de futsal. Advertiu que aqueles que não fizessem "direito", ficariam meia hora a mais "de parte física". Os alunos correram três ou quatro voltas ao redor da quadra. Depois disso, a professora mandou-os dar mais uma volta caminhando, parando em seguida ainda sobre a linha amarela. Depois de mandá-los "tirar distância" uns dos outros - com os braços afastados horizontalmente -,

6 Um bom exemplo, de um texto hoje pouco lembrado, pode ser encontrado em Kunz (1989).

Movimento, Porto Alegre, v. 9, n. 2, p. 89-112, maio/agosto de 2003 
iniciou uma série de exercícios, comandando-os posicionada no centro da quadra. Ela iniciou a contagem, que deveria ser secundada por eles, que deveriam contar em voz alta (geralmente até quinze). A contagem do exercício polichinelo era diferente: deveria acontecer de um até quinze, e retroceder de quinze até um, totalizando trinta repetições. Em determinado momento a professora advertiu que eles não estavam contando alto o suficiente (R2A, 26/06/02).

Os alunos terminaram a corrida e se posicionaram sobre a linha amarela. Como havia um número maior de alunos na aula de hoje, a professora mandou-os fazer duas fileiras ao invés de apenas uma, como costuma acontecer. Os alunos tiraram distância, com os braços afastados horizontalmente, sem a professora terpedidoou mandado. Como nas aulas passadas, eles fizeram os exercícios de alongamento e aquecimento contando as repetições em voz alta (R3A, 28/06/02).

Em praticamente todas as aulas observadas, tanto da turma masculina quanto feminina, percebemos uma excessiva valorização, por parte da professora, dos rituais de disciplinamento relacionados especialmente às atividades realizadas a título de "aquecimento". Como dito anteriormente, essas atividades variavam muito pouco, quase prescindindo da atuação da professora e de qualquer mediação reflexiva por parte dos/as alunos/as. Ao que tudo indica, esses rituais constituíam a própria razão de ser das aulas, recebendo, inclusive, mais peso e importância do que a parte principal.

Sob outro ponto de vista, o fato das aulas serem repetitivas e possuírem a mesma estrutura, parece corresponder a uma certa "concepção pedagógica" da professora. Segundo nos relatou (E1A, 21/11/02), suas aulas são fruto de anos de experiência, sendo desenvolvidas de forma a facilitar seu trabalho e agradar seus/as alunos/as. Nas suas palavras,

...eu, a professora Stela ${ }^{7}$ de Educação Física, eu fui evoluindo com o tempo através de quê? De pesquisa, procurando, tentando melhorar as minhas aulas... pra facilitar pra mim e pros meus alunos. Pra mim poder dizer: "pô hoje eu dei uma aula tranqüila, legal". O queque é tranqüila? É quando você não se incomoda. Então, pra que eu tivesse sucesso na aula sem me incomodar muito, sem me estressar muito... porque ter quarenta horas, você tem que se dividir de manhã e de tarde, então fui criando oquê? Métodos que facilitasse pra mim e satisfizesse as crianças. (sic)

Nesse quadro, não parece sem sentido o fato dos rituais disciplinares ganharem uma maior importância na dinâmica das

7 Os nomes que aparecem nesta citação, assim como nos demais casos, foram alterados a fim de garantir o sigilo em relação à identidade da fonte. A transcrição de diálogos das entrevistas e mesmo das observações mantém, ao máximo possível, a linguagem empregada. 
aulas, uma vez que a principal preocupação explicitada pela professora era evitar maiores "incômodos". Dessa forma, com uma rotina de trabalho estabelecida através da repetição, na qual os alunos/as desenvolvem um modus operandi e sabem previamente quais são seus papéis e o que deles/as é esperado, a professora consegue administrar suas energias para cumprir sua extenuante carga horária.

A segunda face da determinação do modelo esportivo nas aulas manifestava-se na constante valorização da performance dos/as alunos/as, algo cristalizado nas expectativas da professora. Em vários momentos pudemos perceber a promoção e a valorização da competição e do "bom" desempenho nas aulas, tanto por meio das exigências técnicas nas atividades, quanto nos incentivos "morais" verbalizados pela professora, manifestos também no comportamento dos/as alunos/as. Em nossas anotações no caderno de campo lê-se (R5A, 05/07/02), por exemplo, que:

a professora exigiu que todos os alunos fizessem o exercício do polichinelo com sincronia. Um aluno começou poucos segundos depois dos demais, e com isso fez toda a série em descompasso. Ao final da série de trinta repetições, contadas em voz alta, a professora mandou que repetissem mais uma vez a série. Os alunos reclamaram, dizendo que as meninas faziam os exercícios de qualquer forma e ela não as mandava repetir. Alguns deles imitaram de forma caricata a maneira como as meninas supostamente executavam o polichinelo. No entanto, eles tiveram que repetir a série como havia sido mandado.

Uma outra questão importante relaciona-se com a comparação feita pela professora entre os desempenhos de meninos e meninas, como pode ser lido em nossos relatórios: “durante praticamente todos os jogos a professora apoiava e/ou reclamava verbalmente das jogadas 'certas ou erradas' dos alunos. Em determinado momento ela gritou: "vamos, se mexam suas moças"” (R4A, 28/06/02); ou ainda: “os meninos estão sérios e parecem sem vontade de jogar. A professora se irrita mais ainda e diz: 'Vou trazer saia e tamanco para vocês nas próximas aulas. Vocês estão com medo de jogar?'” (R7A, 31/07/02).

O paradoxo é que na medida em que discursivamente a professora aponta que o objetivo das aulas não era a melhoria da performance (RlA, 25/06/02, ENTREVISTA 1A, 21/11/02), as estruturas do treinamento permaneciam a tônica, com os reforços positivos e negativos vinculados ao desempenho. Importante é a comparação, por parte da professora - mas também dos alunos -, entre os desempenhos de meninas e meninos. Às primeiras é atribuído o papel de paradigma de inferioridade na prestação es-

Movimento, Porto Alegre, v. 9, n. 2, p. 89-112, maio/agosto de 2003 
portiva, sendo a comparação com elas, para os meninos, sinal de menoridade. Repete-se aqui a máxima ainda não superada, de que o esporte - símbolo civilizador, de complexidade e de organização da corporalidade - é atividade masculina, relegando-se ao feminino as características de incompletude, proximidade com a natureza, com o espontâneo e com a infantilidade. A professora não esconde sua preferência no trabalho com os meninos, expressa diretamente tanto em nossas observações - como registrado em nosso caderno de campo: "é bom dar aulas para os guris, porque menina é muito chata" (R15A, 26/08/02); ou ainda: "em comparação com os meninos, as meninas são umas "medonhices" (R10A, 07/08/02) - quanto na entrevista. Segundo diz, os meninos são mais "dedicados" e "têm objetivo de aprender o esporte" (E1A, 21/11/02).

\section{Esporte Escolar: rendimento esportivo $x$ "aprendizagem de valores"}

Um elemento que aparece com bastante força na análise parcial dos dados das sessões de treinamento e dos jogos do grupo/equipe pesquisado diz respeito à existência de uma tensão entre os discursos vinculados, por um lado, à performance esportiva e, por outro, a uma suposta "aprendizagem de bons valores" por meio do esporte. Essa tensão se faz clara tanto nas falas do professor/técnico, durante a "tradicional" conversa com os alunos/atletas nos momentos que antecediam os treinos propriamente ditos, durante os intervalos entre o primeiro e o segundo tempos das partidas oficiais, ou mesmo na entrevista que nos concedeu, quanto nas falas dos pais e mães que acompanhavam constantemente os filhos não apenas nos jogos, mas também nos treinamentos.

$\mathrm{Na}$ entrevista realizada com o professor/técnico, ele nos contou que o primeiro e principal objetivo do esporte escolar em geral, e da suas escolinhas em específico, era "educativo" e não "montar uma equipe para ganhar". Essa preocupação com o aspecto pedagógico do esporte aparece também em nosso caderno de campo, no qual se lê, por exemplo, um relato da conversa do professor/técnico com os alunos/atletas antes de iniciar as atividades de uma determinada sessão de treinamento: “...quando a gente fala para vocês para manter uma disciplina, não é só para levar de uma categoria para outra. Isso aqui [o treinamento] é um aprendizado. Eu quero que vocês tenham uma noção

Movimento Porto Alegre, v. 09, n. 2, p. 89-112, maio/agosto de 2003 
de tudo, não só de técnica. Vocês têm que ouvir. É preciso que vocês tenham disciplina se quiserem ser alguém na vida" (R4B, 18/11/02). Outro exemplo aparece em uma conversa que o professor/técnico teve conosco ao final de um dos treinamentos (R2B, 11/11/02). Segundo nos disse, seu trabalho no Esporte Escolar é "diferenciado", não sendo exatamente "voltado para o rendimento", e que a direção da associação esportiva que representa a escola lhe dava essa "liberdade". Disse também que procurava trabalhar mais os elementos de "aprendizagem do esporte", citando como exemplo os aspectos disciplinares e valores como "humildade". Ele fez, no entanto, a ressalva que se um dia vier a ser "cobrado" por seus superiores, para que seus alunos/atletas vençam as competições, então o trabalho passaria a ser "diferente", ou seja, mais voltado para o rendimento esportivo. Essa perspectiva de "trabalho diferenciado" também foi exaltada na entrevista, quando afirmou não fazer processo de seleção para suas escolinhas, procurando trabalhar com o maior número possível de alunos/atletas. O professor/técnico também disse não haver nenhum tipo de cobrança por parte dos seus superiores para a diminuição do número de alunos nas suas turmas, visando, por exemplo, um maior rendimento esportivo, já que seu trabalho "tem dado certo, tem dado resultados positivos". Ele se refere ao bom desempenho competitivo da equipe, já que seu grupo de alunos /atletas obteve a primeira colocação na competição oficial que disputou durante o período de nossas observações. Desta forma, o possível conflito entre uma preocupação "mais formativa" e outra mais vinculada aos resultados competitivos, acaba não se concretizando, o que não livra o professor, no entanto, de conviver com uma série de ambigüidades, como veremos mais adiante.

Essa preocupação do professor/técnico em ressaltar, sobretudo discursivamente, os aspectos positivos do esporte no que diz respeito à aprendizagem de valores (como disciplina, determinação, humildade, etc), aparece de diferentes maneiras nas sessões que observamos. A primeira delas se manifesta na exigência colocada aos alunos/atletas em relação ao desempenho escolar. Como pode ser lido em nossos relatórios, aqueles que obtivessem notas baixas ou que porventura estivessem faltando demais à escola, seriam privados da participação nos treinamentos, sobretudo nos coletivos, ou, quando fosse o caso, com a perda da posição de "titulares" da equipe. Exemplar é, nesse sentido, uma conversa do professor/técnico com seus alunos/atletas:

Movimento, Porto Alegre, v. 9, n. 2, p. 89-112, maio/agosto de 2003 
“João, eu vou falar uma coisa para você que vale para todo mundo. Você está [durante] a semana toda mentindo que saiu cedo [da aula], mentindo para sua avó. Eu não quero isso. É o método que eu tenho para selecionar vocês. Se vocês rodarem, não adianta reclamar. O João tava colocado [no time], aí foi para direção" (R3B, 13/1 1/02). A preocupação em associar o desempenho esportivo ao desempenho escolar fica evidente também na entrevista, quando professor disse que sempre procurava saber como andavam as "notas" dos seus alunos/atletas nas demais disciplinas, e que valorizava o desempenho escolar deles, inclusive como critério para "escalar o time". Nas suas palavras, a configuração ideal pode ser traduzida na seguinte máxima: "aluno bom de bola e bom de escola".

Esse discurso surge do professor/técnico surge também com freqüência ao comparar o comportamento "disciplinar" dos alunos/atletas com o de uma categoria com menor idade. A comparação foi feita geralmente no sentido de estabelecer uma relação entre idade e comportamento, sendo que os mais velhos deveriam ser, em tese, mais "comportados". Esse procedimento visava criar algum tipo de constrangimento nos mais velhos. Anotamos: "Roberto [professor/técnico] reuniu os meninos no centro da quadra. Iniciou reclamando que eles demoravam demais quando ele os chamava para conversar. Disse em seguida que os alunos da categoria pré-mirim, embora sejam mais novos, eram mais disciplinados em relação ao horário, que quando ele os chamava, obedeciam prontamente" (R2B, 11/11/02). Segundo nos revelou o aluno João, esse artifício também era usado com bastante freqüência pelo professor/técnico nas conversas que precediam as partidas que a equipe costumava disputar nos diversos. Nas suas palavras, "ele [o professor/técnico] fala bastante do pré-mirim, porque o pré-mirim é isso, porque tá jogando muito bem, pra gente sentir um pouco de vergonha, assim que entendo (...). Pra gente se tocar que os menores estão ganhando e a gente tá perdendo. Daí, é pra gente demonstrar mais vontade no jogo" (E2B, 19/12/02).

Nesse quadro, o da valorização da aprendizagem de aspectos disciplinares por meio do esporte, inscreve-se ainda um outro elemento: a referência feita pelo professor/técnico aos ídolos esportivos que seriam "exemplos" para seus alunos/atletas. Para ele, o jogador Zico seria um "exemplo completo", tanto no que diz respeito à "vida esportiva" quanto à "vida particular" (E3B, 19/12/02). Revelou ainda que não cita atletas como Pelé, Garrin-

Movimento Porto Alegre, v. 09, n. 2, p. 89-112, maio/agosto de 2003 
cha ou Romário como "modelos" para seus alunos. Na sua opinião, todos eles teriam tido "problemas" nas suas vidas privadas. Fala abertamente do segundo quando diz que foi "alcoólatra" e do terceiro, que embora considere um "craque" assim como os anteriores, é indisciplinado e "sai na noite" (ibidem). O atleta Romário era usado como "exemplo negativo" também nas chamadas "preleções", que o professor costumava realizar nos momentos iniciais das sessões de treinamento e especialmente antes do início das partidas ainda no vestiário. ${ }^{8}$ Em nossos relatórios lê-se, por exemplo, a descrição de uma conversa entre o professor/técnico e seus alunos/atletas momentos antes do início de uma das partidas observadas:

O professor reuniu os alunos e começou uma conversa com eles. Disse ter iniciado falando de disciplina (...) porque haveria equipes que perdem jogos por conta, justamente, desse aspecto. Falou que o Leão [técnico da equipe do Santos Futebol Clube] era um técnico "disciplinador" (pareceu simpatizar com esse técnico) e que não concordava com o técnico Renato Gaúcho, do Fluminense, porque ele seria muito permissivo em relação ao jogador Romário, que era autorizado a "ir para a festa". Comentou que o Fluminense ficou em $4^{\circ}$ lugar no último Campeonato Brasileiro, e que se o $2^{\circ}$ lugar, no contexto brasileiro, especialmente no futebol, já não era lembrado, que se imaginasse, então, $04^{\circ}$.

É importante destacar, ainda no que se refere a esse aspecto, que o discurso que valoriza determinados comportamentos disciplinares, personificados na imagem construída do jogador Zico, parecia ser incorporado também pelos alunos/atletas, como fica evidente na transcrição de um trecho onde o aluno/atleta André (E4B, 20/12/02) falava dessa personalidade pública que considerava "exemplo" de comportamento. É importante que se lembre que esse aluno/atleta, assim como boa parte dos seus colegas de equipe, possuía 12 anos de idade. Isso significa que ele provavelmente não viu o jogador Zico atuando em uma partida de futebol, sobretudo, no período em que esse atleta se encontrava em maior evidência no cenário esportivo brasileiro.

Pergunta: Tem algum atleta, ou jogador ou ator que você mais gosta?

Resposta: Que eu mais... Jogador que eu mais gosto, acho que éo Zico.

P: OZico? Por que ele é de quem vocêmais gosta?

R: Porque ele é um grande jogador e é um exemploné?

8 Sobre as imagens de Romário na imprensa, consulte-se Guedes (1998).

Movimento, Porto Alegre, v. 9, n. 2, p. 89-112, maio/agosto de 2003 
P: Porque ele é um exemplo?

R: Porque ele não bebe, não fuma...

P: Então vocêacha que além dele ter sido um grande jogador, ele tem comportamentos adequados. Éisso?

R: É.

P: E você acha isso importante para um jogador de futebol?

R: É, acho. Muito importante.

P: Por que você acha muito importante?

R: Porque se, por exemplo, ele era um jogador que só vivia como as normas do clube dizia. Tem outros jogador que já sai pra beber à noite, vai pra uma boate. E eu acho que isso aí não é certo. Jogador foi contratado pra jogar futebol.

P: Certo... E você conhece algum jogador famoso que faça isso?

R: Romário. (E4B, 20/12/02).

No entanto, esse discurso de valorização do esporte como "espaço de aprendizagem" parece encontrar dificuldades de compatibilização com a necessidade de rendimento desejado/esperado dos alunos/atletas, frente, sobretudo, aos resultados nas partidas dos campeonatos. Exemplo dessa difícil conciliação aparece em nosso caderno de campo (R2B, 11/11/02), quando o professor/técnico conversava com seus alunos/atletas a respeito da classificação da equipe para a fase final de uma competição:

O professor disse aos alunos que eles precisam ter mais "malícia". Disse também que outra equipe que também está classificada para a fase final do campeonato não émelhor do que a deles, mas têm mais "malandragem". Nesse sentido, seu time precisa também ser "malandro". Para exemplificar aquilo que ele estava falando, o professor perguntou se os alunos viram o jogo do Campeonato Brasileiro de Futebol [de 2002] entre Flamengo e Portuguesa, quando ojogador Lúcio da Portuguesa vez um gol saindo do meio de campo e driblando quase todo o time do Flamengo. O professor comentou em seguida que um fato semelhantejá havia acontecido em jogo da sua equipe, e que esse "tipo de gol" acontecia por "medo" de fazer falta e parar a jogada. Nesses casos, os alunos/atletas deveriam fazer a falta, por exemplo, puxando a camiseta do jogador, evitando que ele fizesse o gol, pois, segundo disse, era por conta de um gol dessa natureza que muitas vezes acabavase perdendo umjogo.

Outro exemplo onde aparece, com bastante força, a contradição exposta acima se refere ao comentário do professor/técnico em relação às reclamações de seus alunos/atletas quanto ao fato de estarem sendo empurrados durante os jogos dos campeonatos que a equipe participava, sem a correspondente marcação da infração por parte da arbitragem (E3B, 19/12/02). Ele comen-

Movimento Porto Alegre, v. 09, n. 2, p. 89-112, maio/agosto de 2003 
tou que costuma falar para seus alunos que às vezes seria necessário revidar esses empurrões, mas não de forma "agressiva". Ressaltou que freqüentemente não se trata de faltas violentas, mas sim de uma certa "malandragem", o fato de um atleta empurrar o outro. Destacou ser contrário à violência e que ser "malandro" seria diferente de ser violento. Comentou que um dos seus alunos/atletas havia aprendido em pouco tempo - considerando o período que participava dos treinamentos da modalidade - a "bater, a dar umazinhas" (Ibidem). Lamentou, inclusive, que sua equipe seria pouco "malandra" e que desejava que usassem mais a falta como recurso para parar as jogadas e por vezes evitar um gol. ${ }^{10}$ Ao final, destacou que a "ingenuidade" de seus alunos pode ter como causa o seu próprio comportamento, já que se considera uma pessoa bastante "calma" e que isso acaba "passando" para eles. ${ }^{11}$

Esse elemento surge também nas falas dos pais e mães que, como dito anteriormente, acompanhavam seus filhos tanto nas partidas oficiais dos campeonatos, quanto nas sessões de treinamento. Em nossos relatórios lê-se freqüentes reclamações de que o professor/técnico teria muita "paciência", que seria pouco exigente em relação ao desempenho dos alunos/atletas. Para mães e pais, a origem do problema residiria no fato do professor/técnico não ser exatamente um "técnico", mas um "professor de

9 Sobre o tema da malandragem na sociedade brasileira e no futebol, consulte-se os vários trabalhos de Roberto DaMatta, principalmente o clássico Carnavais, malandros e heróis: para uma sociologia do dilema brasileiro (DAMATTA, 1979), bem como os trabalhos de Soares (1994) e Dutra e Vaz (2001).

10 No que diz respeito a essa questão, um dado chama a atenção: o Índice de Fair Play (IFP) - que é estabelecido através da fórmula IFP $=$ (faltas 1$)+$ (cartões amarelos 5) + (cartões vermelhos 10) - da equipe mirim, que é treinada pelo professor/ técnico que entrevistamos e cujas sessões de treinamento observamos, figura entre os cinco piores de um total de vinte e uma equipes que disputam o Campeonato Estadual Mirim de Futsal neste ano de 2003. A situação da equipe infantil - que possui vários alunos/atletas que faziam parte da equipe observada no ano anterior - é um pouco melhor em relação ao mesmo índice. Dentre vinte e três equipes que disputam o Campeonato Estadual dessa categoria, seu Indice de Fair Play se encontra entre os dez piores. (Fonte: Home page da Federação Catarinense de Futebol de Salão).

11 É importante destacar que o professor/técnico não pôde ficar no banco de reservas durante as partidas observadas devido ao fato ter sido "suspenso". Tal suspensão aconteceu por causa de uma "discussão"com um dos árbitros de uma partida - da qual foi expulso - dias antes de iniciarmos nossas observações. Segundo revelou, o relatório da arbitragem, que explicava os motivos de sua expulsão, continha acusações infundadas, e que sua suspensão, baseada no referido relatório, teria sido injusta" (E3B, 19/12/02).

Movimento, Porto Alegre, v. 9, n. 2, p. 89-112, maio/agosto de 2003 
Educação Física", como fica claro na declaração de uma mãe que assistia a um treinamento (R1B, 06/11/02): “Roberto [o professor/técnico] tem paciência demais, porque um técnico tem que ensinar às crianças a ter garra e coragem no jogo, tem que ensinar a lutar até o fim, pois isso o esporte também ensina. Mas o Roberto não tem que prestar conta de vencer e por isso que não se importa com estas coisas. Roberto é professor de Educação Física e não técnico".

As falas dos alunos/atletas também evidenciam a contradição entre o discurso de "aprendizagem de valores" e a necessidade de rendimento. O primeiro aparece com pouca força, apenas nos momentos em que os alunos/atletas se referem ao "exemplo positivo" de Zico e "negativo" em relação a Romário, como mencionado anteriormente. Já o segundo parece ter maior peso nas falas dos jovens entrevistados, quando estabelecem uma diferenciação entre as aulas de Educação Física e as sessões de treinamento do Esporte Escolar. Esse último seria, na opinião de André, mais organizado metodologicamente, já que "só se treina futsal e não outra coisa", ao contrário da Educação Física, que tem aulas "mais relaxadas" e a "pessoa fica livre" e "faz o que quer" (E4B, 20/12/02). Essa também é a opinião de João, que considera existir uma grande diferença entre ambas. Segundo afirmou, nas aulas de Educação Física "os alunos ficam mais à vontade", enquanto que no "treino [esporte escolar] é mais sério, é mais para o jogo" (E2B, 19/12/02). Paulo destacou não haver muita diferença entre o Esporte Escolar e a Educação Física mas, no entanto, prefere o primeiro à segunda, pois nele "se treina mais" e se "aprende mais" (E1B, 19/12/02). ${ }^{12}$ Por outro, os alunos/atletas aspiram seguir "carreira" como jogadores profissionais e manifestaram o desejo de treinar mais um dia na semana, pois consideravam duas sessões insuficientes. André achava necessário treinar "mais coisas" do que de costume, destacando as mais atividades para o "condicionamento físico", pois ele "prepara mais o jogador" (E4B, 20/12/02).

12 Dos três entrevistados, somente Paulo, que estuda em outra instituição, freqüenta as aulas regulares de Educação Física. João e André, que estudam na escola investigada, são "dispensados" das aulas de Educação Física pelo fato de participarem dos treinamentos do Esporte Escolar. A opção por não participar também das aulas de Educação Física parece ser dos próprios alunos/atletas, devido a sobrecarga de atividade que isso acarretaria. No entanto, quando estudavam nas primeiras séries do ensino fundamental $\left(1^{\mathrm{a}}\right.$ a $4^{\mathrm{a}}$ série), ambos freqüentavam as aulas regulares de Educação Física e os treinamentos do futsal na época, na categoria fraldinha (até 10 anos).

Movimento Porto Alegre, v. 09, n. 2, p. 89-112, maio/agosto de 2003 
Nesse quadro, qual seja, o da tensão entre o rendimento esportivo desejado/esperado dos alunos/atletas e o aprendizado de "bons valores" por meio da prática esportiva, inscreve-se ainda um outro elemento: a exigência dos alunos/atletas jogarem mesmo estando machucados. Em nosso caderno de campo (R6B, 25/ 11/02) anotamos uma conversa durante uma sessão treinamento entre o professor/técnico com um aluno/atleta um dia antes da rodada do Campeonato da Grande Florianópolis. O menino, que jogava na posição de goleiro, dizia ao primeiro que não iria treinar neste dia e tão pouco jogar a partida do dia seguinte pois tinha chutado a trave e machucado o pé. Seu médico havia recomendado repouso. No entanto, no dia seguinte este mesmo aluno revelou que jogaria a partida atendendo ao pedido de seu professor/técnico, como pode ser lido em nossas anotações (R7B, 26/11/02): "Fernando vem até mim e diz que vai jogar. Pergunto sobre seu dedo machucado e ele responde que Roberto [professor/técnico] pediu para que ele jogasse". Fato semelhante aconteceu na partida final do referido campeonato, quando o aluno/ atleta Paulo, que também é goleiro, jogou machucado. Em nossos relatórios (R9B, 17/12/02) é possível ler a seguinte passagem: “o goleiro Paulo estava com o hálux lesionado e mancava. Perguntei se ele tinha se machucado e ele respondeu que sim. Roberto comentou que achava que Paulo tinha machucado a mão, mas quando viu que a contusão era no pé, exclamou: 'mas no pé!?', como se dissesse que não tinha sido nada, ou pelo menos algo com gravidade". Paulo jogou durante todo o tempo e nossas anotações revelam que o professor/técnico reclamou várias vezes do seu desempenho que, na sua opinião, estava "irreconhecível" (Ibidem).

Ainda com relação a esse fato, Paulo nos contou em entrevista $(E 1 B, 19 / 12 / 02)^{13}$ que quando se machucou na véspera da partida final do campeonato mencionado acima, sua mãe teria dito que ele iria jogar a "final" de qualquer forma, especialmente pelo fato do jogo ser contra o principal rival da equipe na cidade. Disse ainda, que sua mãe lhe falou isso enquanto ele aplicava uma compressa de gelo sobre a lesão.

13 A entrevista aconteceu dois dias depois da referida partida onde Paulo jogou machucado. Ele estava usando uma tala metálica para imobilização da lesão, que, segundo nos contou, teria sido uma "luxação do hálux". Também é importante mencionar que Paulo disputou mais um jogo depois da final do campeonato de futsal. Ele disputou essa partida representando uma equipe de futebol de campo. Durante esse último jogo sentiu muitas dores e solicitou para ser substituído por outro atleta.

Movimento, Porto Alegre, v. 9, n. 2, p. 89-112, maio/agosto de 2003 
Outro ponto que aparece com freqüência nos relatórios é a comparação que o professor/técnico estabelece entre seus jogadores e atletas de outras equipes, notadamente as de futebol profissional. Elas procuravam dar esperanças de que, com "disciplina, humildade e determinação", é possível alcançar o estrelato. Exemplar, nesse sentido, foi a conversa do professor/técnico com seus alunos/atletas numa das sessões de treinamento. Na ocasião, ele reclamava das ausências no treino: "fica difícil escalar o time para o jogo, porque vocês querem ver jogo do Avaí ${ }^{14} \mathrm{em}$ vez de treinar. Só que aqui é uma oportunidade de vocês estarem no gramado mais tarde e não na arquibancada" (R1B, 06/11/02). Comparação semelhante foi feita também nos momentos que antecediam à partida final do campeonato (R9B, 17/12/02):

Roberto falou erepetiu que o título do Campeonato Citadino seria importante para o currículo dos alunos. Citou o exemplo do jogador Robinho, do Santos, que se tornou um destaque a partir da metade do último campeonato Brasileiro de futebol. Disse que assistiu a uma reportagem na televisão que mostrava o Robinho jogando nas categorias de base do futsal. Como exemplo, falou de dois jogadores locaisque estãona Seleção Brasileira Sub-17defutsalouestãojogandono Figueirense ou Avaí. Depois comentoua respeitodojogador Marcel, queénatural de Florianópolis e que tinha "jogado muito" no últimojogo da seleção brasileira de futsal.

O recurso aos exemplos extraídos dos jogos televisionados, tanto dos campeonatos de futebol de campo quanto de futsal, é freqüente por parte do professor/técnico. Ele afirmou incentivar seus alunos/atletas para assistirem esses jogos na televisão, e também que costumava discuti-los com eles. Ressaltou que as transmissões esportivas podem ter uma influência positiva em relação ao esporte escolar. Citou, por exemplo, o fato dos locutores mencionarem que determinado jogador começou sua carreira no futsal e lá obteve sua "base", ou determinada característica de jogo, especialmente no drible, que provinha da iniciação esportiva no futsal. Ainda de acordo com o professor/técnico, tal fato motivaria os alunos/atletas a "fazer melhor" o futsal para mais tarde serem jogadores de futebol de campo, já que o segundo é mais prestigiado do que o primeiro (E3B, 19/12/02).

A expectativa de alcançar o estrelato como jogador profissional de futebol é confirmada pelos alunos/atletas entrevistados (E1B, 2B, 19/12/02; e 4B, 20/12/02). Como mencionado anteriormente, Paulo, André e João manifestaram interesse em seguir

14 Ele se refere ao Avaí Futebol Cube, tradicional equipe de futebol de Florianópolis, atualmente disputando a segunda divisão do campeonato nacional.

Movimento Porto Alegre, v. 09, n. 2, p. 89-112, maio/agosto de 2003 
jogando futebol, inclusive com respaldo e apoio familiar. Se tivessem que optar entre o futsal e futebol de campo, a preferência pelo segundo seria unânime. Embora gostassem de jogar futsal, afirmaram que as possibilidades de projeção no cenário esportivo nacional seriam maiores através do futebol de campo. Exemplar, nesse sentido, é a seguinte passagem (E2B, 19/12/ 02): "Pergunta: se você tivesse que optar por uma carreira de [jogador de] futebol de campo ou de futebol salão [futsal], o que você escolheria? (...) Resposta: Depende, porque no futebol de campo tu é mais visível (...). Porque no futsal a pessoa não..., como eu vou falar, não é muito famosa (...). Tem gente que nem conhecesse o que que éfutebol de salão".

\section{Algumas considerações}

Não é novidade a presença do esporte como conteúdo central da Educação Física escolar, mesmo a ponto de se constituir não apenas como único tema de ensino, mas de se materializar em apenas uma modalidade a ser escolhida por alunos e alunas para todo um semestre. Como já foi dito acima, essa condição coloca em cheque o lugar social da Educação Física como disciplina de conhecimento, uma vez que não há qualquer outro critério que não seja a vontade individual de professores/as e alunos/as para a eleição de um esporte a ser praticado nas aulas. Por outro lado, talvez não seja a modalidade esportiva exatamente o conteúdo central das aulas de Educação Física, mas os processos de disciplinamento corporal que se estruturam em seu entorno. Salta aos olhos a importância que os rituais de organização (aquecimento, formação das crianças em fileiras e/ou colunas, contagem dos exercícios, etc.) têm na estruturação das aulas.

Desse quadro faz parte a segregação entre meninas e meninos, principalmente no que se refere à reafirmação das primeiras como paradigma de inferioridade esportiva - e, portanto, disciplinar, volutiva, de destreza e habilidade - expressa de forma costumeira pela professora. Compõe esse mesmo contexto a preocupação de Stela em "facilitar seu trabalho" e "agradar os alunos". Ora, em um ambiente pouco compromissado com a produção e disseminação de um saber instituído e conseqüente, algo que se manifesta no número reduzido de aulas e na ausência completa de reposição, nada mais razoável do que a procura de um processo que seja menos complexo e mais linear. Ao mesmo tempo isso contrasta com a própria lógica do aprendizado esportivo, que ao exigir disciplina, vontade e empenho - assim

Movimento, Porto Alegre, v. 9, n. 2, p. 89-112, maio/agosto de 2003 
entende a professora -, não torna possível a própria realização, tornando-se, assim, uma caricatura, uma paródia de si mesmo.

Há que se considerar, no entanto, que nas condições de boa parte do professorado, e no contexto analisado isso não foi diferente, os/as professores/as possuem uma carga de trabalho muito extensa e desgastante, sofrendo com o sol, o frio, a depauperação da voz, a brutalidade das relações profissionais e assim por diante. Essas questões, que determinam parcialmente a dinâmica pedagógica, precisam ser consideradas tanto em pesquisas sobre os processos de escolarização do corpo, quanto em programas de formação inicial e continuada.

Por sua vez, a ambigüidade do Esporte Escolar aparece em dois planos: na oscilação do peso da disputa pela vitória em contraposição à formação dos alunos/atletas, algo que o professor-técnico da equipe procura conciliar de forma discursiva, mas que a própria dinâmica do esporte acaba impedindo que aconteça, e na oposição ente Educação Física e Esporte.

No que se refere à primeira questão, atualiza-se uma pergunta antiga que acompanha constantemente as crianças, ainda que ela não seja verbalizada: o que vale no esporte é ou não vencer? A resposta elas aprendem na prática, pouco importando os discursos conciliatórios do professor/técnico. Isso fica claro, por exemplo, na celebração do sacrifício, valorizado como prova de superação e generosidade, ao se motivar alguém a competir, mesmo estando lesionado/a.

Um outro elemento que compõe esse quadro é a força do discurso midiático a respeito dos jogadores de futebol, reforçando as normas e valores que devem "formar" um atleta, como é o caso da dicotomia entre as imagens dos jogadores Zico e Romário. Pouco importa que essas imagens correspondem de fato à verdade, ou que poucas crianças tenham visto o ídolo dos anos oitenta jogar, uma vez que o mito pode prescindir da realidade objetiva, mas não das narrativas, para afirmar-se.

É preciso destacar ainda a força que o futebol de campo exerce no imaginário das crianças e mesmo do professor-técnico, que encaram o futsal como uma etapa para o possível estrelado nos gramados. A plena significância do futebol no Brasil, aliada a uma ainda peculiar presença do futsal entre nós, compõe um quadro ainda não de todo analisado, que carece de mais investigação.

Por fim, no que diz respeito à hierarquia entre o Esporte Escolar e a Educação Física, ela não apenas é reafirmada por

Movimento Porto Alegre, v. 09, n. 2, p. 89-112, maio/agosto de 2003 
todos os sujeitos/atores, quanto é naturalizada pelas estruturas de funcionamento dos respectivos espaços pedagógicos.

Vale, então, seguir investigando a educação do corpo na escola, tanto no aprofundamento das formas que sacramentadas pela investigação, como o Esporte e a Educação Física, quanto apontando para outros lugares e tempos das pedagogias corporais. É preciso lembrar que sem a empiria e a paciência para lidar com ela, não é possível conhecer melhor as práticas com que lidamos diariamente. Restam, entre várias questões, aquela que pergunta se é possível reunir todas as formas e desdobramentos da educação do corpo na escola em um só nexo, para além - mas também para dentro - das aulas de Educação Física e de Esporte Escolar.

\section{Sobre el Deporte en la escuela: paradojas y ambigüedades}

Resumen: el objetivo del trabajo es discutir algunos resultados de una investigación en curso que investiga aspectos de la educación del cuerpo en la escuela. Fueran investigadas por medio de observaciones sistemáticas y entrevistas clases de Educación Física y de deporte en una escuela pública de Florianópolis/SC. Los resultados muestran el predominio de deporte en la Educación Física aparecen como una parodia de sí mismo y la ambigüedad de Deporte en la escuela, entre los imperativos de la competición y los discursos sobre la formación humana por medio de su práctica.

Palabras-claves: Deporte Escolar, Educación física, Educación de Cuerpo, Industria cultural, Teoría Crítica de Sociedad.

\section{On Sport at School: Paradoxes and Ambiguities \\ Abstract: the aim of this paper is to discuss some results of a research in process, whose objective is to investigate aspects of the education of the body in the school. Physical education and sport at a public school of Florianópolis/SC were researched by systematic observations and interviews. The results show the prevalence of sport and its norms and values in the Physical Education as parody of itself, and the ambiguity of Sport at School, between the imperatives of the competition and the speeches about the human formation by sporting practices. \\ Keywords: Sport at School, Physical Education, Education of Body, Culture Industry, Critical Theory of Society.}

Movimento, Porto Alegre, v. 9, n. 2, p. 89-112, maio/agosto de 2003 


\section{Referências}

ADORNO, T. W. Résumé über Kulturindustrie. Gesammelte Schriften 10-1. Frankfurt am Main: Suhrkamp, 1997a.

ADORNO, T. W. Das Schema der Massenkultur. Gesammelte Schriften 4. Frankfurt am Main: Suhrkamp, 1997b.

ADORNO, T. W. Negative Dialektik. Gesammelte Schriften 6. Frankfurt am Main: Suhrkamp, 1997c.

BRACHT, V.; ALMEIDA, F. QUINTÃO. A política de esporte escolar no Brasil: a pseudovalorização da educação física. Revista brasileira de ciências do esporte. Campinas, v. 24, n. 3, p. 87-101, maio 2003.

DAMATTA, R. Carnaval, malandros e heróis: para uma sociologia do dilema brasileiro. Rio de Janeiro: Zahar, 1979.

VAZ, A. F., DUTRA, T. S. Violence in the soccer: an exploratory study in a small city of the south of Brazil In: 6th Annual Congress of European College of Sport Science, 2001, Cologne. Book of Abstracts. Cologne: Strauss, 2001. p.1289 1289

GUEDES, S. L. O Brasil no campo de futebol: estudos antropológicos sobre os significados do futebol brasileiro. Rio de Janeiro: EDUFF, 1998.

HORKHEIMER, M.; ADORNO, T. W. Dialektik der Aufklärung: Philosophische Fragmente. Gesammelte Schriften 3 (Adorno). Frankfurt am Main: Suhrkamp, 1997.

KUNZ, E. O esporte enquanto fator determinante da Educação Física. Contexto e Educação, ljuí, ano IV, n. 15, 1989. p. 63-73.

SOARES, A. J. A malandragem no gramado. Vitória: UFES, 1994.

VAZ, A. F. Políticas públicas para o esporte e o lazer em Santa Catarina: reflexões e considerações. Revista de Educação Física/UEM. Maringá, vol. 12 n. 1 , p. $89-96,1^{\circ}$ sem $2001 \mathrm{a}$.

VAZ, A. F. Técnicas corporais e cuidados com o corpo em ambientes educacionais: aspectos da formação de professores e professoras. Motus Corporis, Rio de Janeiro, v. 8, n. 2, p. 55-66, 2001b.

VAZ, A.F.; BASSANI, J.J.; \& SILVA, A. S. da. Identidades e rituais na educação do corpo na escola: um estudo em aulas de educação física no ensino fundamental. Motus Corporis, Rio de Janeiro, v. 9, n. 2, 2002, p. 23-39.

Movimento Porto Alegre, v. 09, n. 2, p. 89-112, maio/agosto de 2003 